\title{
Editorial
}

\section{Bridge Over Troubled Water}

... is a beautiful song about giving a helping hand to someone caught in a situation of distress. And there is broad consensus around the world that the digital platform markets are caught in troubled waters. A few mighty rivers run so high and so fast that they are drowning smaller creeks around them and carrying away anyone riding them. Different attempts to contain these massive flows have been made, but they were not strong enough. This has led to a widely visible enforcement gap, because the tools needed to build solid bridges for smaller rivals and consumers were either missing or not properly applied so far.

To bridge this enforcement gap, a variety of techniques can be used and are under discussion in different jurisdictions. At the national level, these efforts focus more on amendments to the general competition rules. This shall allow the national competition authorities to catch more anti-competitive mergers and business practices in digital platform markets. The most recent changes brought into German competition law show the way forward. By lowering the intervention threshold for abusive conduct below the current dominance level, the Bundeskartellamt will be able to act more widely and more quickly against such practices. The current reform debate in the USA, under the new administration, also tends to point in this direction, namely amending the antitrust rules to allow for more efficient enforcement.

By contrast, the recent proposals of the European Commission for the Digital Markets Act (DMA) of 15 December 2020 rest upon a very different architecture for this ambitious 'bridge-building' project. Relying on its powers to harmonise national rules of the EU Member States to create a single market, the Commission seems to place greater trust on supra-national ex ante regulation than on stricter competition law enforcement. While an overhaul of the latter had been discussed extensively, this reform has been dropped for the time being and may (or may not) reappear at a later stage, depending on the progress made with the DMA.

Under the proposed new rules, which will be directly binding in all EU Member States without further transposition by national legislators, digital platform companies shall be obliged to notify the Commission themselves if they fulfil three different quantitative criteria, based on their own assessment. Relying on this notification, the Commission would then designate them as gatekeepers. In the absence of such a notification, the Commission could however also proceed with the gatekeeper designation following a market investigation based on a more qualitative assessment. The main targets of this process are the 'digital giants' from outside the EU. 
The designation will trigger a long list of prohibitions and obligations related to the provision of the gatekeepers' core platform services, without further intervention by the Commission in each individual case. The black and grey lists contained in the DMA proposal are directly inspired by the recent enforcement practice of the Commission and the national competition authorities with the ex post competition rules, including both restrictive agreements and abusive unilateral conduct.

Such a process, combining key competition principles with a detailed new procedure and tight deadlines, would undeniably have the benefit of greater effectiveness compared to the current situation. According to recent statements, the Commission seems to rely on a high compliance level and faithful cooperation by the companies concerned. However, past experience with such co-regulation models suggests that their overall effectiveness should not be over-estimated. It can by no means be taken for granted that the whole mechanism will fall into place without any major debate and legal disputes. Companies will certainly use all possible ways to contest their gatekeeper position, by rebutting presumptions and invoking suspensions and exemptions, all foreseen explicitly in the proposals. If designated gatekeepers do not comply with the prohibitions and obligations set out in the black and grey lists of the DMA, the Commission shall be entitled to impose remedies including break-ups. All of this will have to take the form of Commission Decisions subject to judicial review.

Reliance on ex ante regulation to overcome certain obstacles for market entry and undistorted competition is not new in the EU. There is a wealth of experience with such models in former monopolised sectors like telecoms end energy. These models however largely sit on the shoulders of national authorities, while the Commission only intervenes where necessary. A major difference with the DMA proposal lies in a highly centralised approach. The Commission is foreseen as the main actor, merely assisted by Member States through an Advisory Committee.

The responsibility for this task within the Commission has not yet been clarified. Typically, internal market legislation based on Article 114 TFEU, like the DMA, would not be implemented by DG COMP. However the black and grey lists in the proposal are based on antitrust case law, and the market investigation and decision making powers are a blueprint of Regulation 1/2003. Thus it can be assumed that DG COMP would want to retain a strong role for the DMA. This might trigger conflicts with its antitrust enforcement powers which will continue to apply in digital markets. Since the same procedures will be applicable both ex ante and ex post, it will not be easy for platform providers to predict the outcome. The Commission will be in a position to pursue them with two different instruments, which may lead to over-enforcement in certain cases. On the other hand, smaller rivals of the leading platforms will get additional tools to make themselves heard before the Commission. They are the intended beneficiaries of the new rules, together with consumers.

This overview shows that many details of the DMA proposal, both on substance and procedure, remain to be solved in the legislative process, which will probably take us 
into the year 2023. Much water will continue to flow until the new bridge is ready. We at CoRe will keep a close eye on all of this, both with our publications and our events. Our recent online webinar ${ }^{1}$ already brought together leading experts in this field and sparked interesting discussions. There is more to come.

We are pleased to see that the present issue of our journal has a focus on these topics. In the articles section, John Weche and Thomas Weck address tacit collusion and the use of online pricing algorithms in gas stations, which have been difficult to tackle so far. To close this gap, they consider the need for new competition tools and possibly ex ante regulation, such as the DMA. Kiran Desai presents an overview of the developments that led to the DMA proposal and then adds an analysis of the need for a reform of the merger rules in pursuit of the same objective. Richard Masquelier examines the (slim) track record of interim measures decisions at EU and national level and offers meaningful explanations, to conclude that reforms are needed in order to make this instrument more effective, part of which might be found within the DMA proposal.

The country reports section this time contains an overview by Jeroen Dewispelaere and Sandrine Verstraete on the allocation practicse for radio spectrum in Belgium, a summary prepared by Satu-Anneli Kauranen of the Finnish NCA's decision to impose fines in the first resale price maintenance case in a decade, a note from Pernille Edh Hasselgård on a Norwegian start-up acquisition being blocked to protect competition on digital platforms, as well as a short description of the Spanish legal framework and recent trends regarding cartel fines by Jerónimo Maillo.

Our case notes section features an analysis by Amaryllis Müller and Koo Asakura of the CJEU ruling in the Telenor case about the compatibility of zero-rating with the net neutrality principle, as well as a comment by Francesco Rizzuto on the Court ruling about the independence of national regulatory authorities in the Slovak Republic. The book review drafted by Jan Broulík comments on Bruce Wardhaugh's 'Competition, Effects and Predictability: Rule of Law and the Economic Approach to Competition'. An updated version of the most read post from our CoRe Blog by Friso Bostoen, also the topic of an upcoming CoRe webinar ${ }^{2}$, discusses the Epic v Apple case concerning App Store fees for in-app purchases.

In troubled times, both for healthy competition and life in general, we all long for solutions and solid bridges to walk on. At least in the former field, we hope that we can give you some inspiration with our journal!

Robert Klotz Managing Editor

1 'The New Competition Tool of the EU in Practice' (Online seminar, 18 January 2021) <https://www.lexxion.eu/en/events/the-new-competition -tool-of-the-eu-in-practice/> accessed 11 February 2021.

2 'App Store Antitrust: A Case Study of the Gaming Industry' (Webinar, 1 March 2021) <https://www.lexxion.eu/en/events/app-store-antitrust-a -case-study-of-the-gaming-industry/> accessed 11 February 2021. 